\title{
FESS при носна полипоза
}

\author{
FESS for nasal polyposis
}

\section{Хр. Златанова ${ }^{1}$, К. Асенова ${ }^{1}$, Ст. Стоянов² \\ ${ }^{1}$ УНГ-клиника ВМА - София \\ гУНГ-клиника МИ, МВР - Софрия}

\author{
Hr. Zlatanov ${ }^{1}$, K. Assenova ${ }^{1}$, St. Stoyanov² \\ ${ }^{1}$ ENT Clinic MMA, Sofia \\ ENT Clinic MI, MI, Sofia
}

Abstract

For a period of 2 years at the ENT Clinic of MMI have been treated surgically 46 patients with nasal polyposis. In 26 has been done conventional polypectomy and in the other 20 has been chosen FESS (Functional Endoscopic Sinus Surgery). Control examinations have been done 6 months postoperatively. For comparison have been used 4 criteria: 2 of which - subjective (selfesteem by VAS of the quality of nasal breathing and secretion) and 2 - objective (anterior rhinoscopy and nasal endoscopy and acoustic rhinometry). The results showed significant difference in favor of FESS, both for subjective and objective outcome criteria. Keywords: FESS; Polypectomy; Nasal polyposis.

\section{Резюме}

За период от две години в УНГ-клиниката на ВМА са лекувани хирургично 46 пациенти с диагноза носна полипоза. От тях при 26 е приложена стандартната конвенционална хирургична интервенция (полипектомия), а при останалите 20 е предпочетена ендохирургична методика - FESS (Functional Endoscopic Sinus Surgery). Контролните прегледи бяха извършвани шест месеца след операцията, като за сравнение между двата метода бяха използвани четири показателя. Два от тях субективни (самооценка на пацента за: качеството на носното дишане и силата на носната секреция) и два обективни (предна риноскопия и акустична ринометрия). Получените резултати показаха чувствителна разлика в полза на FESS както по отношение на самооценката за качеството на живот на пациентите, така и по отношение на обективната находка при горепосочените изследвания

Ключови думи: FESS, полипектомия, носна полипоза

\section{Въведение}

Ендоскопската синус хирургия като оперативна методика е описана за пръв път през 1985 г. от проф. Хайнц Щамбергер. През същата година проф. Дейвид Кенеди въвежда и наложилото се масово в практиката и научната литература име на методиката - FESS (Functional Endoscopic Sinus Surgery). През следващите две десетилетия тя навлезе широко в оториноларингологичната хирургична практика, като понастоящем се превърна в основен микроинвазивен (щадящ) метод за оперативно лечение при носна полипоза, хроничен риносинуит, доброкачествени новообразувания на носа и околоносните кухини, орбитална декомпресия и др. Като подгрупа на FESS се развива и така наречената балонна пластика на синусите (balloon sinuplasty), представляваща най-съвременния метод за лечение на хроничната недостатьчност на вентилацията и дренажа на околоносните кухини, чиито резултати са повече от обещаващи.

\section{Материал и методика}

В настоящото изследване са включени 46 пациенти на възраст между 18 и 67 години, лекувани хирургично в УНГ-клиниката на ВМА - София за период от две години. Пациентите са разделени на две групи. При първата група от 26 болни е предпочетена конвенционалната полипектомия, а при останалите 20 е извършена FESS. Сравнението между двете групи беше 
направено на базата на четири показателя. Два от тях са субективни: като показател I - самооценка на пацента за качеството на носното дишане и показател II - сила на носната секреция. Останалите два са обективни и са отбелязвани като показател III - находка при предна риноскопия и ендоскопия и показател IV - резултати от акустична риноме- трия. Контролен преглед за оценка на оперативния резултат беше извършван 6 месеца след операцията.

За оценка по първите два показателя бяха използвани визуално - аналогови скали, които болните попълваха по време на контролния преглед 6 месеца след операцията (Фиг. 1).

Фиг. 1. ВАС за носна обструкция и наличие на назална секреция шест месеца след оперативната интервенция

Име възраст

Адрес

Моля определете качеството на дишането през носа върху скалата

\begin{tabular}{|l|l|l|l|} 
& & & \\
\hline Нормално носно дишане & Леко затруднено носно дишане & Средно затруднено носно дишане & Силно затруднено носно дишане
\end{tabular}

Моля определете силата на носната секреция върху скалата

\begin{tabular}{|c|c|c|c|} 
& & & \\
\hline Липса на хрема & Лекостепенна хрема & Средно тежка хрема & Тежка хрема
\end{tabular}

Според третия показател посредством предна риноскопия и ендоскопско изследване на носа пациентите бяха разпределяни в три групи:

- Група A - без наличие на носни полипи

- Група В - наличие на полипозни формации само в средния носов ход

- Група С - наличие на полипозни формации и в долния носов ход

По четвъртия показател пациентите бяха разпределяни в две групи:

- Група I - с данни за лекостепенна носна обструкция или липса на такава

- Група II - с данни за сериозна носна обструкция

\section{Резултати}

При обработката на данните по критерии I и II на пациентите от групата с ковенционална полипек- томия се получиха следните резултати:

- Осем души са отговорили, че имат тежка степен на носна обструкция.

- Шест души са отговорили, че са със средна степен на носна обструкция.

- Десет души са отговорили, че са с лека степен на носна обструкция.

- Двама души са отговорили, че са с незапушен Hoc.

При групата, оперирана посредством FESS, резултатите от таблици №1 са следните:

- Девет пациенти са отговорили, че са с незапушен нос.

- Шест души са отговорили, че са с лека степен на носна обструкция.

- Пет са отговорили, че са със средна степен на носна обструкция.

Табл. 1 и Фиг. 2 представляват съпоставка между двете основни групи пациенти по първия показател (самооценка за носното дишане).

Табл. 1. Съпоставка между пациенти с конвенционална и ендоскопска полипектомия според самооценката на носното дишане

\begin{tabular}{|l|c|c|c|c|}
\hline & $\begin{array}{c}\text { Нормално носно } \\
\text { дишане }\end{array}$ & $\begin{array}{c}\text { Леко затруднено } \\
\text { носно дишане }\end{array}$ & $\begin{array}{c}\text { Средно затрудне- } \\
\text { но носно дишане }\end{array}$ & $\begin{array}{c}\text { Силно затруднено } \\
\text { носно дишане }\end{array}$ \\
\hline $\begin{array}{l}\text { Пациенти след конвенционал- } \\
\text { на полипектомия }\end{array}$ & $2(7.7 \%)$ & $10(38.5 \%)$ & $6(23 \%)$ & $8(30.8 \%)$ \\
\hline $\begin{array}{l}\text { Пациенти след ендоскопска } \\
\text { полипектомия }\end{array}$ & $9(45 \%)$ & $6(30 \%)$ & $5(25 \%)$ & 0 \\
\hline
\end{tabular}




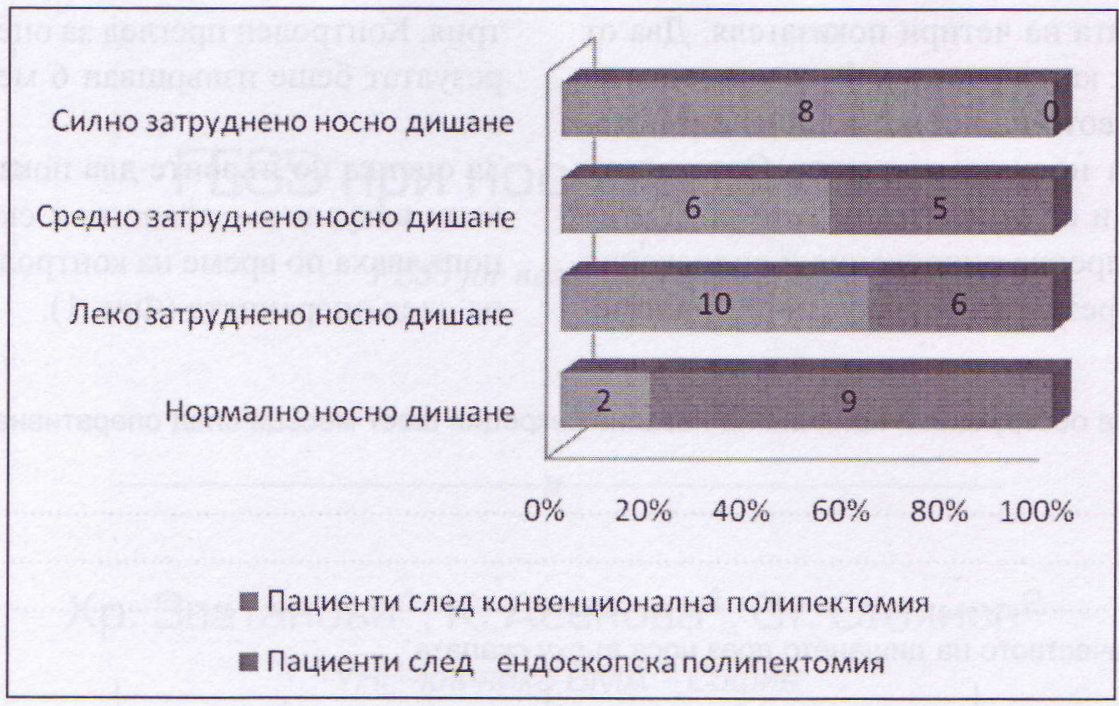

Фиг. 2. Съпоставка между пациенти с конвенционална и ендоскопска полипектомия според самооценката на носното дишане

По показател II получихме следните резултати (Табл. 2, Фиг. 3):

При групата с конвенционална полипектомия:

- Двама души са отговорили, че нямат хрема.

- Осем души са отговорили, че имат лека степен на хрема.

- Девет пациенти са отговорили, че са със средна по тежест хрема.
- Седем души са отговорили, че имат тежка хрема При оперираната посредством FESS група резултатите са следните:

- Седем души са отговорили, че нямат хрема

- Осем души са отговорили, че имат лека хрема

- Пет пациенти са отговорили, че са със средна по тежест хрема.

Табл. 2. Съпоставка между пациенти с конвенционална и ендоскопска полипектомия според самооценката на носната секреция

\begin{tabular}{|l|c|c|c|c|}
\hline & $\begin{array}{c}\text { Липса на } \\
\text { хрема }\end{array}$ & $\begin{array}{c}\text { Лекостепенна } \\
\text { хрема }\end{array}$ & $\begin{array}{c}\text { Средно тежка } \\
\text { хрема }\end{array}$ & Тежка хрема \\
\hline Пациенти след конвенционална полипектомия & $2(7.7 \%)$ & $8(30.8 \%)$ & $9(34.5 \%)$ & $7(27 \%)$ \\
\hline Пациенти след ендоскопска полипектомия & $7(35 \%)$ & $8(40 \%)$ & $5(25 \%)$ & 0 \\
\hline
\end{tabular}

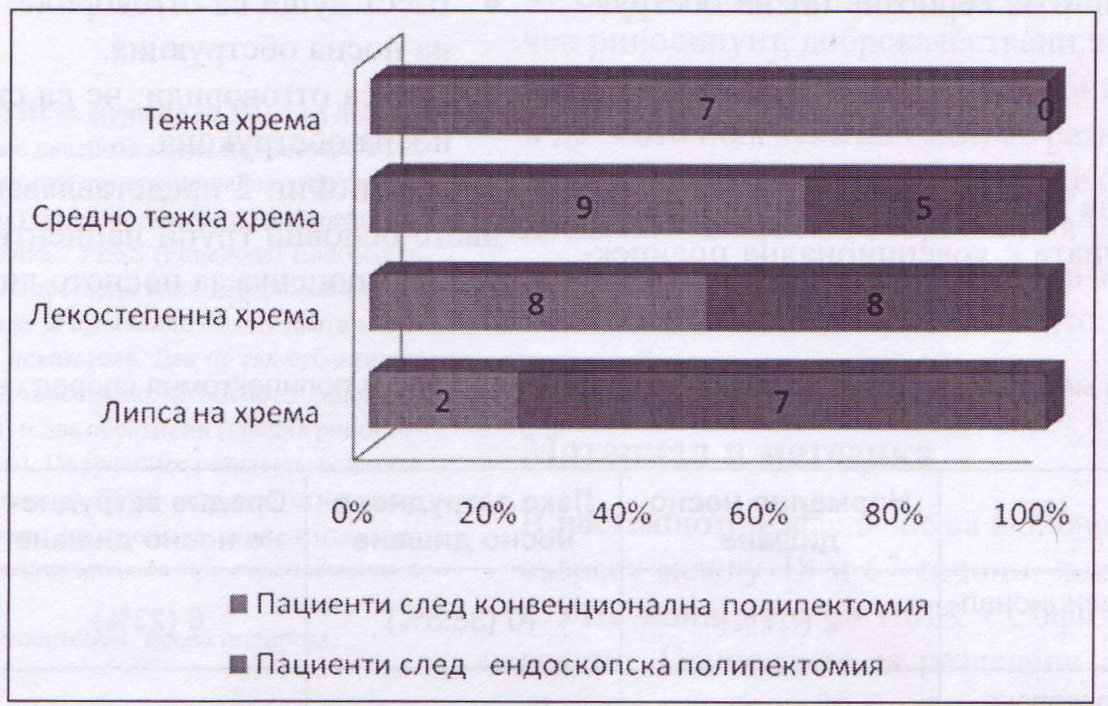

Фиг. 3. Съпоставка между пациенти с конвенционална и ендоскопска полипектомия според самооценката на носната секреция 
По третия показател обработката на данните показа следното (Табл. 3, Фиг. 4)):

Пациенти с конвенционална полипектомия:

- Към Група А са причислени трима пациенти

- Към Група В - десет пациенти

- Към Група С - тринайсет пациенти
Пациенти с FESS:

- Към Група А са причислени дванайсет пациенТи

- Към Група В - шест пациенти

- Към Група С - двама пациенти

Табл. 3. Съпоставка между пациенти с конвенционална и ендоскопска полипектомия според обективното наличие на носни полипи

\begin{tabular}{|l|c|c|c|}
\hline & Група А & Група В & Група С \\
\hline Пациенти след конвенционална полипектомия & $3(11.5 \%)$ & $10(38.5 \%)$ & $13(50 \%)$ \\
\hline Пациенти след ендоскопска полипектомия & $12(60 \%)$ & $6(30 \%)$ & $2(10 \%)$ \\
\hline
\end{tabular}

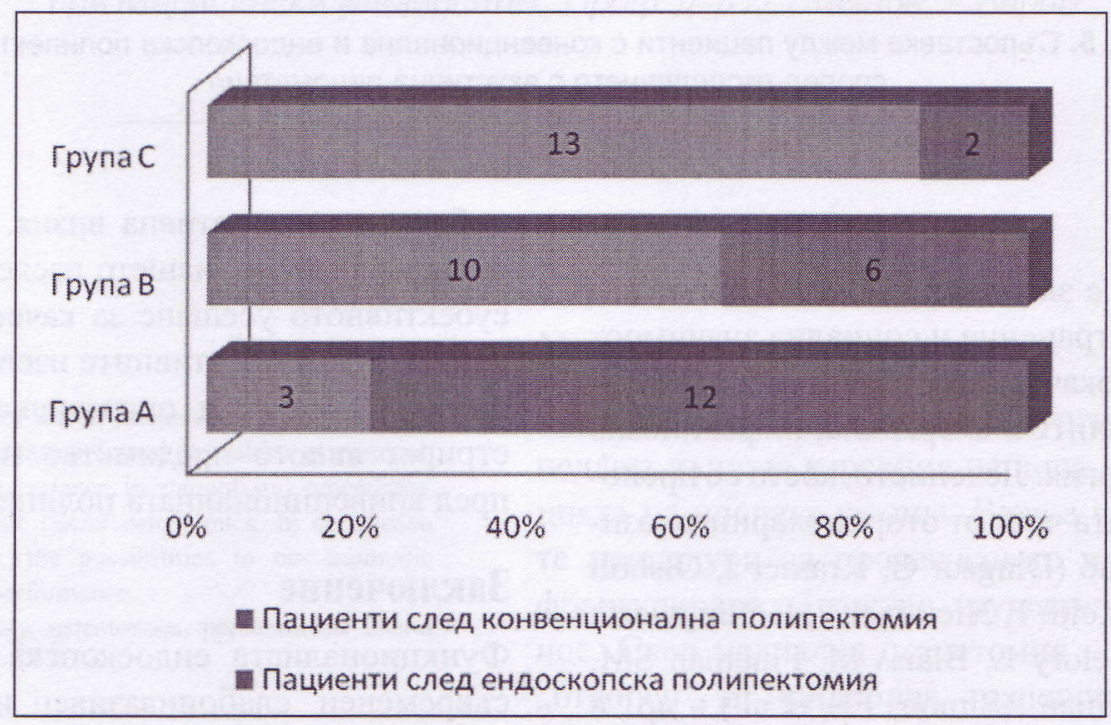

Фиг. 4. Съпоставка между пациенти с конвенционална и ендоскопска полипектомия според обективното наличие на носни полипи

При разглеждане на резултатите от акустичната ринометрия се установи (Табл. 4, Фиг. 5):

Оперирани по конвенционалната методика - към Група I (лекостепенна носна обструкция или липса на такава) са причислени осем пациенти, а към
Група II (с данни за сериозна носна обструкция) - осемнайсет пациенти.

Оперирани посредством FESS - към Група I са причислени шестнайсет болни, а към Група II четири болни.

Табл. 4. Съпоставка между пациенти с конвенционална и ендоскопска полипектомия според изследването с акустична ринометрия

\begin{tabular}{|l|c|c|}
\hline & Група I & Група II \\
\hline Пациенти след конвенционална полипектомия & $8(30.8 \%)$ & $18(69.2 \%)$ \\
\hline Пациенти след ендоскопска полипектомия & $16(80 \%)$ & $4(20 \%)$ \\
\hline
\end{tabular}




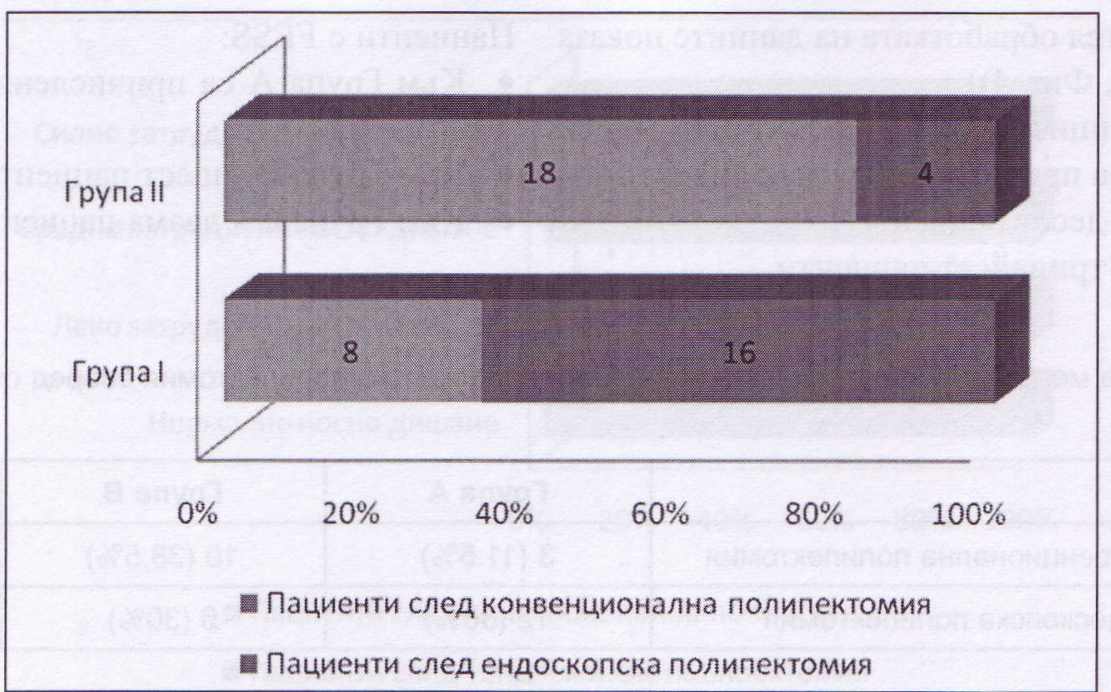

Фиг. 5. Съпоставка между пациенти с конвенционална и ендоскопска полипектомия според изследването с акустична ринометрия

\section{Обсъждане}

Носната полипоза е заболяване, което добива все по-голямо разпространение и социална значимост на фона на рязко покачващия се брой на пациентите, страдащи от ринити с алергична, инфекциозна или смесена етиология. Лечението, което се препоръчва от по-голямата част от оториноларинголозите в световен мащаб (Dingsor G, Kramer J, Olsholt R, Soderstrom T. ; Keith P, Nieminen J, Hollingworth K, Dolovich J. ; Bielory L, Blaiss M, Fineman SM, Ledford DK, Lieberman P,Simons FE, et al.) и др., е оперативно отстраняване на полипозните формации посредством FESS и последваща поддтржаща консервативна терапия, най-често назални кортикостероиди и перорални антихистамини.

Получените от нас резултати рязко накланят везните в полза на своевременното оперативно лечение на пациентите с носна полипоза посредством прийомите на функционалната ендоскопска синус хирургия. Нейните предимства са безспорни. Освен общоизвестните качества на метода, като микроинвазивност, кратък следоперативен период, добра интраоперативна визия, незначителен риск от кървене и т.н., нашето изследване показва, че и субективното усещане за качеството на живот на пациентите и обективните изследвания, направени шест месеца след оперативната намеса, демонстрират явното предимство на FESS-методиката пред конвенционалната полипектомия.

\section{Заключение}

Функционалната ендоскопска синус хирургия е съвременен, слабоинвазивен и сигурен хирургичен метод за лечение на носната полипоза, даващ възможност за максимално добро почистване на носните ходове и околоносните кухини от полипозните формации и гарантиращ много добро качество на живот на оперираните по този метод пациенти. Ние считаме, че FESS би трябвало да навлезе колкото се може по-масово в хирургичната практика на българските оториноларинголози и по възможност да се превърне в основната хирургична методика за лечение на носната полипоза.

\section{Книгопис}

1. Stammberger H (1985) Endoscopic surgery for mycotic and chronic recurring sinusitis. Ann Otol Rhinol Laryngol 94 (suppl 119): 1-11.

2. Kennedy DW. (1985) Functional endoscopic sinus surgery: technique Arch Otolaryngol 111: 643-649.

3. Kennedy DW (1992) Prognostic factors, outcomes and staging in ethmoid sinus surgery Laryngoscope 102 (Suppl. 57): 1-18.

4. Rowe-Jones JM (1997a) Perennial rhinitis and asthma - the link Allergy, 52 (Suppl 36): 20-28.

5. Sharp HR, Rowe-Jones JM, Mackay IS (1999) Outcomes of endoscopic sinus surgery: correlation with CT score and systemic disease. Clin Otolaryngol 24: 39-42.

6. Virolainen E, Puhakka H (1980) The effect of intranasal beclomethasone dipropionate on the recurrence of nasal polyps after ethmoidectomy. Rhinology 18: 9-18.

7. Mehanna H, Mills J, Kelly B, McGarry G (2002) Benefit from endoscopic sinus surgery Clin Otolaryngol 27: 464-471.

8. Rowe-Jones JM, Mackay IS (1996) Endoscopic sinus surgery in the treatment of nasal polyposis with cystic fibtosis. Laryngoscope 106: 1540-1544.

9. Rowe-Jones JM, Mackay IS (1997b) A prospective study of olfaction following endoscopic sinus surgery with adjuvant medical treatment. Clin Otolaryngol 22: 377-381. 